\title{
A geografia crítica e a economia política
}

Rita de Cássia Ariza da Cruz USP

p. $492-503$

\section{revista}

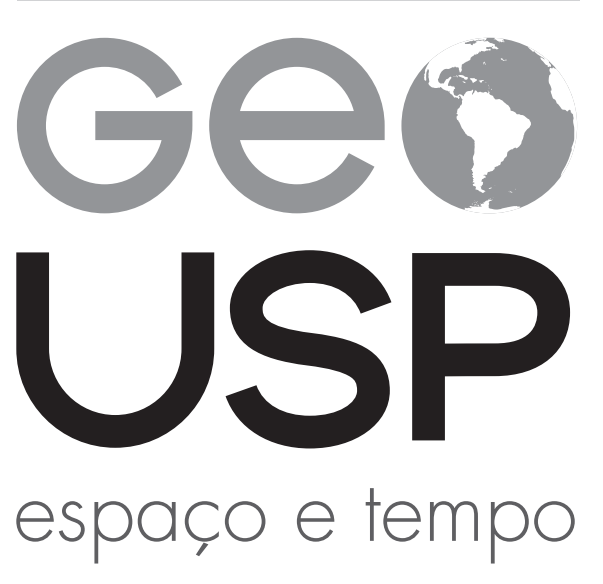

Volume 22 - $n^{\circ} 3(2018)$
Como citar este artigo:

CRUZ, R. C. A. A geografia crítica e a economia política. Geousp - Espaço e Tempo (Online), v. 22, n. 3, p. 492-503, dez. 2018. ISSN 2179-0892.

Disponível em: <https://www.revistas.usp.br/geousp/article/view/152491>. doi: http://dx.doi.org/10.11606/issn.21790892.geousp.2018.152491.

\section{(C) $(1) \Theta$}

Este artigo está licenciado sob a Creative Commons Attribution 4.0 License. 


\title{
A geografia crítica e a economia política
}

\section{Resumo}

Como é amplamente sabido pelos geógrafos, estivemos e ainda estamos muito longe de ter uma unidade na Geografia dada pelo movimento de renovação do pensamento geográfico ocorrido a partir dos anos 1970 e ao qual se chamou Geografia Radical, nos EUA, e Geografia Crítica, na França, na Alemanha e no Brasil, entre outros. A despeito disso, esse foi e é um dos movimentos mais importantes na história do pensamento geográfico. Isso posto, este artigo analisa esse movimento considerando sua relação com a economia política de orientação marxista, destacando o protagonismo de autores brasileiros (entre os quais, diversos professores do Departamento de Geografia da FFLCH-USP) e estrangeiros que concorreram para sua disseminação e consolidação, principalmente no Brasil. Um enfoque especial é dado à noção de desenvolvimento geográfico desigual.

Palavras-chave: Geografia radical. Geografia crítica. Marxismo. Economia política. Desenvolvimento geográfico desigual.

\section{The Critical Geography and the Political Economy}

\begin{abstract}
As it is widely known by geographers, we have been and still are very far from having a unity in Geography given by the movement of renewal of geographic thought that occurred in the 1970s and which was called Radical Geography in the USA and Critical Geography in France, Germany and Brazil, among others. In spite of this, this was and is one of the most important movements in the history of geographic thought. So, this article analyzes this movement considering its relation with the political economy under a Marxist orientation and highlighting the protagonism of Brazilian authors (among which various professors at the Department of Geography of USP) as well as foreign authors who contributed to its dissemination and consolidation, mainly in Brazil. A special focus is given to the notion of uneven geographical development.
\end{abstract}

Keywords: Radical Geography. Critical Geography. Marxism. Political Economy. Uneven Geographical Development. 


\section{Introdução}

Um dos principais protagonistas do movimento de renovação do pensamento geográfico no século XX é o geógrafo Richard Peet (1977), ${ }^{1}$ que, numa entrevista, disse:

Nós fizemos uma revolução na Geografia em dois sentidos. Primeiro, mudamos os atuais interesses entre as diferentes coisas que os geógrafos faziam. Naquele tempo, a Geografia era uma descrição de fatos ou uma Geografia quantitativa do espaço. Ambas estavam distanciadas da atividade humana. Nenhuma dessas Geografias tinhas muito a ver com problemas sociais urgentes. Então, a primeira coisa a fazer era transformar a natureza da Geografia de forma que ela passasse a se preocupar com questões vitais (p. 137).

A segunda coisa era partir, gradualmente, de uma crítica radical para uma Geografia marxista, no final da década de 70 e início dos anos 80. Naquele tempo, a noção de síntese entre marxismo, como um estudo da estrutura social, e a Geografia, como um estudo do meio, do lugar e do espaço - a relação entre Marxismo e Geografia - era completamente desconhecida; ninguém tinha qualquer concepção sobre isto. Na verdade, quando começamos, não compreendíamos o que poderia ser esta conexão (p. 137).

$[\ldots]$ os dois juntos $-\mathrm{o}$ interesse pelo marxismo e o interesse em problemas sociais - transformaram a Geografia e eu acho que tornaram a Geografia muito mais interessante, muito mais engajada, muito mais política, mas também, muito mais teórica e muito mais filosófica. Estas foram as principais diferenças que provocamos. Não creio que a Geografia tenha sido a mesma desde então, felizmente (p. 138).

Os excertos acima evidenciam que mudanças profundas foram operadas no campo da ciência geográfica nas últimas décadas do século XX, com uma extraordinária abertura teórica, metodológica e conceitual a qual, se pode afirmar, não se restringiu à releitura e à assimilação da obra marxista. Pelo contrário, uma das características desse novo momento histórico para a Geografia é justamente o pluralismo metodológico, como aponta Moraes (1997, p. 126) ao referir-se à Geografia Crítica:

A unidade da Geografia Crítica manifesta-se na postura de oposição a uma realidade social e espacial contraditória e injusta... É uma unidade de propósitos dada pelo posicionamento social, pela concepção de ciência como momento da práxis, por uma aceitação plena e explícita do conteúdo político do discurso geográfico. Enfim, é uma unidade ética. Entretanto, estes objetivos unitários objetivam-se através de fundamentos metodológicos diversificados.

\footnotetext{
Professor da Clark University, EUA, e um dos fundadores do movimento conhecido como Geografia Radical, me concedeu uma entrevista em 1996, por ocasião do encontro internacional $\bigcirc$ Mundo do Cidadão - um Cidadão do Mundo, em homenagem ao Prof. Milton Santos e levado a termo no Departamento de Geografia da Faculdade de Filosofia, Letras e Ciências Humanas da Universidade de São Paulo (FFLCH-USP).
} 
Foi, entretanto, por meio do "interesse pelo marxismo e pelos problemas sociais", que a Geografia se aproximou da economia política e "arregimentou" inúmeros geógrafos pelo mundo e pelo Brasil.

No caso brasileiro, especificamente, ao discutir o designativo de crítica, Moraes (1977, p. 112) afirma que este "diz respeito, principalmente, a uma postura frente à realidade, frente à ordem constituída". Para ele, "são os autores que se posicionam por uma transformação da realidade social, pensando o seu saber como uma arma desse processo".

Passemos, então, a abordar mais detidamente, a relação entre renovação do pensamento geográfico e economia política.

\section{A economia política sob uma perspectiva geográfica}

Embora o termo economia política tenha sido cunhado ainda no século XVII, ${ }^{2}$ a economia política constitui-se como novo campo de estudos no século XVIII, segundo Grespan (2014), ${ }^{3}$ tendo Adam Smith (1723-1790) e David Ricardo (1772-1823) como dois de seus mais importantes protagonistas. Como se sabe, Adam Smith é considerado também o grande responsável por fazer da economia uma ciência, para além, portanto, de um simples ramo da filosofia social.

Mas, logo no século XIX, Marx (1818-1883) produz uma profunda crítica da economia política proposta tanto por Adam Smith quanto por David Ricardo, avançando por um debate que desloca a criação de valor da simples exploração da terra e da produção de mercadorias para a força de trabalho. Além disso, Marx supera seus antecessores pelo caminho da dialética, da autonegação, da contradição como constitutivos do modo de produção capitalista e de sua realização histórica, como aponta Grespan (2000, 2001).

A economia política pode ser compreendida, ela mesma, como uma superação em relação às abordagens econômicas clássicas, restritas ao ambiente doméstico e ao espaço privado, ao transpor o foco da análise para o espaço público, para a cidade, para o país, como indica Grespan (2014). ${ }^{4}$

Para além de um corpus científico, entretanto, a economia política pode ser compreendida, também, como uma noção, utilizada para indicar a qualidade de algo, de alguma coisa. Exemplos disso são trabalhos como The political economy of international relations (de Robert Gilpin, 1987), The political economy of industrial policy (de Ha Joon-Chang, 1993), The political economy of health care (de Carolyn H. Tuohy e Sherry Glied, 2011), The political economy of public debt (de Richard M. Salsman, 2017) e The political economy of agriculture and food policies (de Johan F. M. Swinnen, 2018), entre muitos outros de autores estrangeiros.

Entre abordagens de autores brasileiros, podemos citar Economia política da urbanização (de Paul Singer, 1973), Economia política da comunicação (organizado por Valério Cruz Brittos, 2011), Economia política do poder: uma crítica da teoria geral da administração (de João Henrique de Faria, 2004) e Nova economia política dos serviços (de Anita Kon, 2017), entre diversos outros.

2 Antoine de Montchrestein (1575-1621) teria sido aquele que primeiro usou a expressão "economia política", por meio do livro de sua autoria intitulado Tratado de Economia Política, de 1615.

3 Informação fornecida pelo Prof. Jorge Grespan em setembro de 2014, durante aula intitulada A crítica da economia política em Marx.

4 Ibidem. 
Naturalmente, incontáveis abordagens sobre economia política não estão claramente explicitadas nos títulos das respectivas obras, sejam elas artigos científicos, livros ou capítulos de livros. Exemplo disso é a obra do sociólogo Francisco de Oliveira, reconhecida, no seu conjunto, por uma original economia política do Brasil.

Outro exemplo é o filósofo e sociólogo Henri Lefébvre, situado entre os intelectuais do século XX que deixaram um extraordinário legado teórico, metodológico e conceitual, consubstanciado em uma vasta obra no interior da qual se encontra, entre tantas outras contribuições do autor, uma crítica à economia política do espaço.

geógrafo escocês Neil Smith faz parte também desse grupo, considerando-se que sua produção científica centra-se numa economia política do desenvolvimento assim como em uma economia política do espaço, em sentido amplo, e do espaço urbano mais especificamente sem, entretanto, que a "economia política" apareça nos títulos de seus escritos.

O britânico David Harvey, por sua vez, é um dos geógrafos mais conhecidos internacionalmente por produzir uma vasta obra centrada em uma economia política do capitalismo, com abordagens que vão da escala global à escala urbana. Entre muitos de seus livros publicados nos últimos 40 anos sob esta perspectiva, podemos destacar Social justice and the city (1973), The New Imperialism (2003), A brief history of Neoliberalism (2005) e, mais recentemente, Rebel cities: from the right to the city to the urban revolution (2012).

Naturalmente, cada campo disciplinar se apropria da economia política como ciência amalgamando-a a seus próprios pressupostos teóricos, metodológicos e conceituais, o que, no caso da Geografia, resulta na atribuição de uma centralidade, não tão comum a outras áreas do conhecimento, ao espaço e ao território.

Como amplamente sabido, a Geografia, assim como outros campos disciplinares, padeceu, durante muito tempo, da monotonia metodológica imposta pelos postulados positivistas, compreendidos esses como "o conjunto das correntes não dialéticas" (Moraes, 1997, p. 21).

Assim, na chamada Geografia Tradicional, não houve e não teria como haver espaço para uma economia política de base marxista, o que só vai ocorrer na segunda metade do século $\mathrm{XX}$, a partir de um movimento mundial de renovação do pensamento geográfico que, por um lado, sentencia a crise da chamada Geografia Tradicional (Moraes, 1997; Claval, 2017) e, por outro, abre novas perspectivas de análise que culminam na assunção de um pluralismo metodológico. É nesse contexto, do pós-estruturalismo e das filosofias da desconstrução (Claval, 2017), que emerge o movimento conhecido por Geografia Crítica, cuja denominação advém, segundo Moraes (1997, p. 112), "de uma postura crítica radical frente à Geografia existente (seja a Tradicional ou a Pragmática)", levando à ruptura com o pensamento anterior.

Conforme Moraes (1997, p. 119), quem pioneiramente introduziu conceitos marxistas aos estudos geográficos foi o geógrafo francês Pierre George (1909-2006), ao "tentar uma conciliação da metodologia da análise regional com o instrumental conceitual do Materialismo Histórico".

Mas não é apenas do marxismo que a Geografia Crítica se alimenta. Exemplo disso é Milton Santos, que se inspira, também, na filosofia contemporânea e em filósofos como Jean-Paul Sartre para construir uma vasta e profunda contribuição para o movimento de renovação da Geografia e de consolidação de uma Geografia Crítica. 
A inseparabilidade entre autor, obra e contexto (Moraes, 2005) evidencia-se ao chamarmos a atenção para o avanço do processo de globalização, para a terceira revolução industrial, para a reestruturação produtiva, para as duas guerras mundiais, para a queda do muro de Berlim, entre tantos outros acontecimentos marcantes, que diante de tão profundas transformações sociais, econômicas e políticas demandaram dos cientistas sociais, em especial, novos caminhos analíticos.

Essas mudanças somente podem ser compreendidas, portanto, em se levando em conta o contexto histórico, social e econômico do século XX, marcado por transformações profundas e poderíamos dizer menos duradouras que aquelas que marcaram séculos anteriores em função da rapidez com que acontecem ou seja, da "aceleração contemporânea" como postulara Milton Santos.

O processo social e histórico de produção do espaço coloca-se, assim, numa relação dialética com a produção de ideias sobre a produção do espaço, sejam estas voltadas ao planejamento estatal ou privado ou, ainda, reflexões livres, sem qualquer comprometimento com o establishment.

É, assim, no contexto do pós-Segunda Guerra, na efervescência política e econômica do período, que se dão os encontros entre marxismo e Geografia. Falamos em encontros, no plural, com base em Ruy Moreira, segundo o qual:

Por dois momentos deu-se o encontro entre o marxismo e a geografia na história do pensamento geográfico. $O$ primeiro foi a década dos anos cinquenta, no imediato pós-guerra, com o grupo dos geógrafos franceses da geografia ativa (em seu contraponto com a geografia aplicada). $O$ segundo, o recente dos anos setenta, que junta desde os ativistas do periódico Antipode da "geografia radical" até os geógrafos brasileiros da chamada "geografia crítica". Num e noutro momento a relação foi profícua, estimulando a multiplicação de horizontes de olhares tanto na geografia quanto no marxismo, numa interação que de resto há tempos é corrente nos demais campos acadêmicos (Moreira, 2004, p. 21).

"segundo encontro" com a obra marxista influenciou, decisivamente, a aproximação entre Geografia e Economia Política com destaque para geógrafos brasileiros envolvidos no movimento de renovação do pensamento geográfico nesse período. Sem pretender construir uma listagem exaustiva com esses autores-pesquisadores e assumindo o risco de deixar de mencionar vários entre eles, referenciamos, a seguir, alguns, em função, principalmente, de seu legado para a chamada Geografia Crítica.

Começamos mencionando alguns professores do Departamento de Geografia da FFL$\mathrm{CH}-U S P$, os quais, inquestionavelmente, protagonizaram um papel central na disseminação dessa nova forma de pensar e de fazer Geografia, que aproximou este campo disciplinar da economia política.

No que tange à Geografia Agrária, por exemplo, fazemos menção à obra de Ariovaldo Umbelino de Oliveira. Ao apropriar-se da categoria renda da terra, emprestada à Economia Política (Nogueira, 2017), Oliveira produziu uma economia política do campo brasileiro, dedicando especial atenção à região amazônica, o que se pode exemplificar por livros de sua autoria publicados a partir da década de 1980 como Modo de produção capitalista e agricultura (1986), 
Amazônia: monopólio, expropriação e conflitos (1987), Integrar para não entregar: políticas públicas e Amazônia (1988), Agricultura camponesa no Brasil (1991), apenas para mencionar os mais antigos em um amplo número de publicações.

No âmbito da Geografia Urbana, a obra de Ana Fani Alessandri Carlos, dedicada a uma abordagem geográfica, marxista-lefebvriana, da produção do espaço urbano, produz, claramente, uma economia política do espaço e da urbanização, com um foco na escala metropolitana e, especialmente, na cidade de São Paulo. Entre os livros publicados pela autora a partir dos anos 1990, que exemplificam o que ora afirmamos, encontram-se: Espaço e indústria (1990), A (re)produção do espaço urbano (1994), Espaço-tempo na metrópole (2001), A condição espacial (2001). Soma-se a esses livros uma vasta produção de artigos e capítulos de livros.

No subcampo da Geografia das Indústrias, destaca-se a obra de Sandra Lencioni, também de orientação teórica marxista-lefebvriana, cujos estudos apontam para uma economia política da indústria brasileira e paulista, especificamente, ligada a uma economia política da urbanização e da metropolização brasileiras. A título de exemplo, citamos os artigos Reestruturação Industrial no estado de São Paulo: a região da metrópole desconcentrada (1995), A reestruturação da indústria têxtil no estado de São Paulo (1996), Mutations metropolitaines et transformations industrielles à Sao Paulo (1996) e Mudanças na metrópole de São Paulo e transformações industriais (1998) e os capítulos de livro Novos rumos e tendências da urbanização e da industrialização do estado de São Paulo (2004) e O desenvolvimento industrial brasileiro e o processo de concentração industrial (2005).

Uma aproximação com a economia política é também encontrada nos escritos de Milton Santos, sendo exemplos disso livros publicados a partir do final dos anos 1970 como: O espaço dividido: os dois circuitos da economia urbana dos países subdesenvolvidos (1979), A urbanização desigual: a especificidade do fenômeno urbano nos países subdesenvolvidos (1980), Metrópole corporativa fragmentada: o caso de São Paulo (1990) e Por uma economia politica da cidade: o caso de São Paulo (1994).

Para além de uma contribuição à economia política da cidade e da urbanização, a obra de Milton Santos estende-se, também, na direção de uma economia política do espaço e do território, o que se evidencia em obras autorais suas ou em coautoria como é o caso de $O$ Brasil, território e sociedade no início do século XXI, com Maria Laura Silveira e publicado em 2001, no interior do qual o capítulo XIV (Uma ordem espacial: a economia política do território) sintetiza, em certa medida, a proposta teórica contida no livro.

De acordo com Santos e Silveira (2001, p. 289, grifo do original), "cada momento da história tende a produzir sua ordem espacial, que se associa a uma ordem econômica e a uma ordem social e a análise dessa ordem espacial remete os autores ao que os mesmos chamam de uma "economia política do território'”.

Ressalte-se o fato de que a categoria território é central na obra em questão, mas, como afirma Moraes (2013, p. 15):

[...] o conceito de território não aparece como essencial nos primeiros estudos de Milton Santos. Pode-se considerar que em seu período formativo e de consolidação de seu pensamento, abarcando as décadas de 1940 a 1960, tal conceito não emerge com centralidade na estruturação de seus trabalhos. 
A economia política proposta por Santos e Silveira (2001) nesta obra especificamente foca o uso do território e propõe a noção de "território usado" como caminho analítico. Assim, com foco no território brasileiro, os autores abordam a superposição de diferentes divisões do trabalho, associadas a distintas escalas geográficas, que vão do global ao local. Além disso, discutem o uso corporativo e competitivo do território, afirmando que:

À medida que o território brasileiro se torna fluído, as atividades econômicas modernas se difundem e uma cooperação entre as empresas se impõe, produzindo-se topologias de empresas de geometria variável, que cobrem vastas porções de território, unindo pontos distantes sob uma mesma lógica particularista (Santos e Silveira, 2001, p. 291).

A "guerra global entre lugares" é outro aspecto da economia política do território desenhada pelos autores no livro em questão, o que se evidencia por sua abordagem dos processos de reorganização produtiva do território assim como pela análise dos "circuitos espaciais da produção", da circulação territorial e das topologias resultantes dos interesses espaciais estratégicos das empresas.

Tratando-se de uma nova geração de geógrafos, destaca-se Anselmo Alfredo. Entre as publicações de sua autoria que expressam sua aproximação com o marxismo e com a economia política, encontram-se o livro Crítica à economia política do desenvolvimento e do espaço (2013), assim como os artigos Modernização e reprodução crítica. agroindústria do leite e contradições do processo de acumulação (2009) e Negatividade e a crítica à crítica crítica: sobre espaço, tempo e modernização (2010).

$\mathrm{Na}$ Universidade Federal Fluminense, dois nomes se destacaram principalmente nesse movimento de aproximação entre Geografia e economia política: um deles é o geógrafo conhecido por sua participação no processo de renovação do pensamento geográfico brasileiro e na consolidação do movimento da Geografia Crítica, Carlos Walter Porto-Gonçalves, cuja produção evidencia a influência do pensamento marxista e aponta, desde os anos 1980, para uma economia política do meio ambiente e dos movimentos sociais. Alguns de seus livros que exemplificam isso são: Paixão da Terra: ensaios críticos de Ecologia e Geografia (1984) e, mais recentemente, Geo-grafias: movimentos sociales, nuevas territorialidades y sustentabilidad (2001), Amazônia, Amazônias (2001), A globalização da natureza e a natureza da globalização (2006); o outro é Ruy Moreira, que também integra o universo de geógrafos que beberam na fonte de uma economia política marxista; obras de sua autoria apontam para uma economia política do espaço brasileiro, como é o caso dos livros $O$ movimento operário e a questão cidade-campo no Brasil (1984) e Formação do espaço agrário brasileiro (1990), entre os mais antigos, e Formação espacial brasileira: uma contribuição crítica à geografia do Brasil (2011), Geografia do espaço-mundo: conflitos e superações no espaço do capital (2016), que integram sua produção recente.

No plano internacional, David Harvey e Richard Peet foram protagonistas do movimento conhecido como Geografia Radical, anteriormente citado aqui, responsável pela disseminação, primeiramente nos Estados Unidos e daí para o mundo, de uma economia política marxista. A revista Antipode: a Radical Journal of Geography foi fundada em 1969, por professores e estudantes pós-graduação em Geografia na Clark University para disseminar as ideias críticas que começavam a efervescer no ambiente universitário à época, tendo David Harvey como um de seus primeiros colaboradores. Como se lê no sítio da própria revista: 
Desde 1969, o Antipode: A Radical Journal of Geography publicou artigos revisados por especialistas que impulsionam os limites críticos da Geografia, com a intenção de engendrar o desenvolvimento de uma nova e melhor sociedade. Muitos são inspirados pelo pensamento marxista, socialista, anarquista, antirracista, anticolonial, feminista, queer, trans*, verde e pós-colonial; no entanto, a revista sempre acolheu a infusão de novas ideias e o abalo de posições antigas por meio do diálogo e da discussão, nunca se comprometendo com apenas uma visão da crítica. A Antipode está comprometida com as novas, inovadoras, criativas e até agora impensadas arestas radicais da teorização e análise espacial. Seus trabalhos são inovadores, seus argumentos claros desenvolvem o pensamento geográfico e fazem muito mais do que simplesmente adicionar exemplos para apoiar o que já sabemos. Os artigos da Antipode refletem e ampliam os debates do nosso tempo, empurrando literaturas, conhecimento e política para além de suas fronteiras, explorando novos temas e agendas, e colocando novas pesquisas ou análises críticas para trabalhar para fazer intervenções na ordem das coisas (Overview, [s.d.]), tradução nossa). ${ }^{5}$

Vale lembrar que a década de 1960, nos Estados Unidos, foi marcada por protestos históricos organizados pela sociedade civil contra a Guerra do Vietnã (1959-1975) e contra degradações ambientais que se multiplicavam e se evidenciavam pelo país assim como pela luta por direitos por parte da sociedade civil.

Por outro lado, é inquestionável a proximidade entre a Geografia Radical de origem estadunidense e o movimento da chamada Geografia Crítica no Brasil. Elas não só estão juntas no que Moreira (2004) chamou de segundo momento da aproximação entre a Geografia e o Marxismo, mas estão ligadas ontologicamente. Não por acaso, Moreira (2004, p. 28) se refere a esse momento como a "fase da geografia radical/crítica".

\section{A economia política e a noção de desenvolvimento geográfico desigual}

Embora o debate acerca da noção de desenvolvimento desigual e combinado remeta à passagem do século XIX para o século XX, o movimento de renovação do pensamento geográfico promovido pela Radical Geography e pela Geografia Crítica atualiza e renova sua discussão no âmbito de uma economia política no campo disciplinar da Geografia.

A partir do anos 1980, principalmente, o debate sobre desenvolvimento desigual vai ser atualizado à luz das profundas transformações ocorridas ao longo do século XX e, sobretudo, a partir de sua segunda metade. Os mais importantes teóricos do desenvolvimento desigual desse período são, sem dúvida, o geógrafo David Harvey e seu discípulo Neil Smith.

5 "Since 1969 Antipode: A Radical Journal of Geography has published peer-reviewed papers that push Geography's critical edge, intending to engender the development of a new and better society. Many are inspired by Marxist, socialist, anarchist, anti-racist, anticolonal, feminist, queer, trans*, green, and postcolonial thought; however, the journal has always welcomed the infusion of new ideas and the shaking-up of old positions through dialogue and discussion, never being committed to just one view of critique. Antipode is committed to the new, the innovative, the creative, and the heretofore unthought radical edges of spatial theorisation and analysis. Its papers are groundbreaking, their clear arguments develop geographical thinking, and they do much more than simply add examples to support what we already know. Antipode papers reflect upon and extend the debates of our time, pushing literatures, knowledge and politics to and beyond their extant boundaries, exploring new themes and agendas, and putting new research or critical analysis to work to make interventions in the order of things" (Overview, [s.d.]). 
Em vez de discutir uma "lei do desenvolvimento desigual e combinado", Harvey e Smith propõem uma teoria sobre ele, pois como afirmara Smith, Marx "trabalhou consistentemente contra tais universalidades filosóficas argumentando que a filosofia separada da ciência era mera especulação e metafísica e dizendo que a ciência deve partir do real e das condições históricas existentes" (Smith, 1986, p. 91). ${ }^{6}$

Após percorrer um longo caminho analítico por categorias centrais do pensamento marxista, Harvey conclui o livro The limits to capital, originalmente publicado em 1982 (traduzido para o português e publicado no Brasil, pela primeira vez, em 2013), com um capítulo que, em síntese, constitui o âmago de sua proposta teórica sobre o desenvolvimento geográfico desigual. Este capítulo é intitulado Crise na economia espacial do capitalismo: a dialética do Imperialismo. Conforme o autor:

Capitalismo não se desenvolve sobre uma superfície plana dotada de matérias-primas abundantes e oferta de trabalho homogênea com igual facilidade de transporte em todas as direções. Ele está inserido, cresce e se difunde em um ambiente geográfico variado que abarca grande diversidade na liberalidade da natureza e na produtividade do trabalho [...] (Harvey, 2013, p. 526).

Enquanto Harvey se ocupa de produzir uma teoria geral sobre a produção capitalista do espaço e, no interior desta, uma teoria sobre o desenvolvimento geográfico desigual, Smith dedica parte importante de sua produção à construção de uma teoria sobre o desenvolvimento desigual, relacionando, diretamente, a esta, uma teoria sobre gentrificação. ${ }^{7}$

Como assinalamos em artigo publicado em 2018, para Smith (1988), a ideologia burguesa teria propalado a ideia de que o desenvolvimento desigual seria uma espécie de "lei universal da história humana" e, portanto, um processo ao mesmo tempo universal e natural, pressuposto este que foi veementemente negado tanto por ele quanto por Harvey (2013). Segundo Smith (1986, p. 91), uma lei "que pretende explicar todas as instâncias da desigualdade na experiência humana através do tempo e do espaço tanto é abrangente quanto não explica nada". ${ }^{8}$

De acordo com o autor, salvo o fato de que determinadas condições naturais favorecem o desenvolvimento de determinadas atividades ou usos dos recursos da natureza, é, em verdade, "a divisão do trabalho na sociedade a base histórica da diferenciação espacial de níveis e condições de desenvolvimento" (Smith, 1988, p. 152).

Para Smith (1988), o desenvolvimento desigual (ressalte-se que só em algumas passagens o autor faz uso da expressão desenvolvimento geográfico desigual, sendo claro que não há diferença entre estas) deve-se, resumidamente, a duas características-chave do modo de produção capitalista:

6 "[...] worked consistently against such philosophical universals, arguing that philosophy separate from science was mere speculation and metaphysics, and claiming that science ought to begin from real and existing historical conditions" (Smith, 1986, p. 91).

7 Smith (1982, p. 139) afirma: "By gentrification I mean the process by which working class residential neighborhoods are rehabilitated by middle class homebuyers, landlords, and professional developers. I make the theoretical distinction between gentrification and redevelopment. Redevelopment involves not rehabilitation of old structures but the construction of new buildings on previously developed land".

8 " $[. .$.$] which purports to explain all intances of uneveness in human experience, across time and space, is so all-embracing$ as to explain nothing" (Smith, 1986, p. 91). 
(a) à necessidade de acumulação do capital, que leva a "uma franca expansão geográfica da sociedade capitalista, conduzida pelo capital produtivo" (p. 175);

(b) à centralização do capital, "que completa o trabalho de acumulação" (p. 179) promovido pela concentração social do capital, que é uma necessidade da acumulação (p. 177).

Como afirma Smith (1988), "a concentração espacial e o processo de centralização referem-se à localização física do capital e é, desse modo, diferente da concentração e centralização sociais" (p. 176).

No que tange às escalas geográficas, o desenvolvimento desigual manifesta-se em todas elas, embora de diferentes formas. Para Smith, três escalas primárias surgem com a produção do espaço sob o capitalismo: o espaço urbano, a escala da nação-Estado e o espaço global" (p. 196). Segundo o autor:

[...] o impulso em direção à universalidade, sob o capitalismo, traz somente uma limitada igualização dos níveis e das condições de desenvolvimento. $\bigcirc$ capital produz escalas espaciais distintas (espaços absolutos) dentro dos quais o impulso para igualização está concentrado. Mas só pode ser realizado por aguda diferenciação e por contínua diferenciação do espaço relativo, tanto entre as escalas quanto dentro delas. As escalas por si mesmas não são fixas, mas se desenvolvem [... ] dentro do desenvolvimento do próprio capital. E não são impermeáveis; as escalas urbanas e nacionais são produtos do capital internacional e continuam a ser moldadas por ele. Mas a necessidade de escalas separadas e de sua diferenciação interna é fixa. Isto oferece o último elemento básico para a teoria do desenvolvimento desigual (Smith, 1988, p. 211).

\section{Onde ficaria, então, a escala regional?}

Embora aponte as escalas global, nacional e local como escalas primárias resultantes do modo de produção capitalista, Smith (1988, p. 207) afirma:

Na escala das nações-Estado separadas é que o desenvolvimento regional e a diferenciação são importantes. A diferenciação interna dos territórios nacionais em regiões identificáveis é a expressão geográfica da divisão do trabalho, tanto no nível de capitais individuais quanto no da divisão particular de trabalho (em setores). A concentração regional de capital é resultado direto da tendência para a centralização espacial, mas não é um processo tão separadamente definido quanto na escala urbana.

Para Markusen (1981, p. 63), "se as regiões não forem a base ou a arena para o conflito, seu estudo seria desinteressante e talvez não existisse". Markusen discute a região e o regionalismo sob um enfoque marxista e, neste sentido, ressalta a necessidade de uma conotação sociológica, para além da conotação de entidade territorial pura e simples à qual remete a noção de região. Além disso, a autora conclui que "as regiões existem e são significativas para os marxistas apenas como fenômenos empíricos sujeitos a uma análise concreta, histórica e caso a caso" (Markusen, 1981, p. 62). 


\section{Considerações finais}

Como se sabe e se evidenciou neste breve artigo, o movimento de transformação no/ do pensamento geográfico a que historicamente vimos chamando de Geografia Crítica não foi obra individual de um ou de outro geógrafo brasileiro ou estrangeiro. Pelo contrário, a Geografia Crítica resulta de uma espécie de "catarse coletiva", sobretudo se levamos em conta o ocorrido no Encontro da Associação dos Geógrafos Brasileiros (AGB) em Fortaleza, em 1978, cuja história é amplamente conhecida dos geógrafos brasileiros.

Como destaca Ruy Moreira no documentário AGB: assim se passaram 40 anos (AGB, 2018), o movimento estudantil teve papel fundamental não somente na renovação da AGB, mas também e sobretudo na disseminação do marxismo na Geografia brasileira e na construção de novas bases teóricas e epistemológicas para esse campo disciplinar.

O contexto histórico mundial e latino-americano, especificamente, é igualmente fundamental para se compreender a força que ganha esse movimento, contra-hegemônico, oposto a uma ordem (im)posta e que se confunde com a própria luta de movimentos sociais, de trabalhadores e da sociedade em geral pela democracia e por direitos sociais em diversos lugares do planeta.

A Geografia Crítica representa, portanto, na sua origem, uma profunda ruptura em relação a um status quo, a um modo de fazer ciência subordinado ao establishment e tudo o que ele significava em um país que, naquele momento, encontrava-se sob a égide de um regime autoritário.

A aproximação entre Geografia Crítica e Economia Política é fruto, portanto, desse momento de "resgate" da obra e do pensamento marxista, e o seu legado pode ser facilmente reconhecido nos dias de hoje. Gerações de geógrafos formadas nessas últimas quatro décadas tiveram a oportunidade de vivenciar uma disciplina renovada, ainda que essa renovação não se tenha dado em todos os lugares ao mesmo tempo.

A Geografia Crítica espalhou-se, também, pela América Latina por meio de livros de autores brasileiros - alguns traduzidos para o espanhol (como foi o caso de várias obras de Milton Santos), mas também por meio de encontros acadêmicos internacionais, com especial destaque para o Encontro de Geógrafos da América Latina (Egal), criado em 1987 e realizado pela primeira vez em uma cidade no interior do estado de São Paulo.

Por fim, seria um equívoco supor que a Geografia Crítica não caminharia, também, para a sua superação, talvez em direção a uma metageografia (Carlos, 2011). Mas essa história, ou melhor, essa Geografia, encontra-se ainda em construção e somente o futuro poderá revelá-la.

\section{Referências}

AGB. ASSOCIAÇÃO DOS GEÓGRAFOS BRASILEIROS. AGB 78: assim se passaram quarenta anos. 2018. 1 vídeo. Disponível em: http://agbcampinas.com.br/site/2018/docagb78/. Acesso em: 13 jan. 2018.

CARLOS, A. F. A. Crise e superação no âmbito da Geografia Crítica: construindo a metageografia. Geousp - Espaço e Tempo (Online), São Paulo, n. 30, p. 14-28, 2011.

CLAVAL, P. Geo-épistémologie. France: Armand Colin, 2017. 
GRESPAN, J. Marx, crítico da teoria clássica do valor. Dossiê Crítica Marxista, São Paulo: Boitempo, v. 1, n. 12, p. 59-76, 2001.

GRESPAN, J. A crise na crítica à economia política. Dossiê Crítica Marxista, São Paulo: Boitempo, v. 1, n. 10, p. 94-110, 2000.

HARVEY, D. Os limites do capital. São Paulo: Boitempo, 2013.

MARKUSEN, A. Região e regionalismo: um enfoque marxista. Espaço \& Debates, São Paulo, v 1, n. 2, p. 61-99, 1981.

MORAES, A. C. R. Território na geografia de Milton Santos. São Paulo: AnnaBlume, 2013.

MORAES, A. C. R. Ideologias geográficas. São Paulo: AnnaBlume, 2005.

MORAES, A. C. R. Geografia: pequena história crítica. São Paulo: Hucitec, 1997.

MOREIRA, R. Marxismo e geografia: a geograficidade e o diálogo das ontologias. GEOgraphia, Niterói, v. 6, n. 11, p. 21-37, 2004.

NOGUEIRA, A. T. B. A categoria renda da terra: da economia política à geografia agrária. Nera, Presidente Prudente, SP, v. 20, n. 37, p. 13-27, 2017.

PEET, R. Entrevista a Rita de Cássia Ariza da Cruz. Revista Experimental, São Paulo: Laboplan-USP, v. 2, n. 3, p. 137-147, 1997.

SANTOS, M.; SILVEIRA, M. L. Brasil: território e sociedade no início do século XXI. Rio de Janeiro: Record, 2001.

SMITH, N. Desenvolvimento desigual: natureza, capital e a produção do espaço. Rio de Janeiro: Bertrand Brasil, 1988.

SMITH, N. On the necessity of uneven development. International Journal of Urban and Regional Research, v. 10, n. 1, p. 87-104, 1986.

SMITH, N. Gentrification and Uneven Development. Economic Geography, v. 58, n. 2, p. 139-155, 1982. Disponível em: https://www.tandfonline.com/doi/abs/10.2307/143793. Acesso em: 13 jan. 2018. 